\title{
Encapsulation Performance of Layer-by-Layer Microcapsules for Proteins
}

\author{
Marie-Luce De Temmerman, ${ }^{\dagger}$ Jo Demeester, ${ }^{\dagger}$ Filip De Vos, ${ }^{\star}$ and Stefaan C. De Smedt ${ }^{*}{ }^{\prime}$
}

Laboratory of General Biochemistry and Physical Pharmacy, Faculty of Pharmaceutical Sciences, Ghent University, Harelbekestraat 72, 9000 Ghent, Belgium and Laboratory for Radiopharmacy, Faculty of Pharmaceutical Sciences, Ghent University, Harelbekestraat 72, 9000 Ghent, Belgium

*E-mail: stefaan.desmedt@ugent.be

\section{RECEIVED DATE}

To whom correspondence should be addressed. Tel.: +32 926480 47. Fax: +32 926481 89. E-mail: stefaan.desmedt@ugent.be

$\dagger$ Laboratory of General Biochemistry and Physical Pharmacy, Faculty of Pharmaceutical Sciences, Ghent University, Harelbekestraat 72, 9000 Ghent, Belgium

$\$$ Laboratory for Radiopharmacy, Faculty of Pharmaceutical Sciences, Ghent University, Harelbekestraat 72, 9000 Ghent, Belgium

\section{Abstract}

This study reports on the encapsulation efficiency of proteins in dextran sulfate / poly-L-arginine based microcapsules, fabricated via Layer-by-Layer assembly (LbL). For this purpose, radiolabeled proteins are entrapped in $\mathrm{CaCO}_{3}$ microparticles followed by $\mathrm{LbL}$ coating of the $\mathrm{CaCO}_{3}$ cores and subsequent dissolving of the $\mathrm{CaCO}_{3}$ using EDTA. To allow to improve protein encapsulation in LbL microcapsules, we studied all steps in the preparation of the microcapsules where loss of protein load might occur. The encapsulation efficiency of proteins in LbL microcapsules turns out to be strongly dependent on both the charge and molecular weight of the protein as well as on the number of polyelectrolyte bilayers the microcapsules consist of. 
Keywords: microcapsules, protein delivery, calcium carbonate, Layer-by-Layer, microparticles

\section{Introduction}

Nano- and microparticles, made from a plethora of materials, are currently widely investigated as drug carriers. Since a couple of years, a number of groups became interested in so named polyelectrolyte capsules as drug carriers. Such capsules are fabricated by the Layer-by-Layer (LbL) technique based on the consecutive adsorption of oppositely charged polymers on colloidal cores used as sacrificial templates. ${ }^{1}$ Subsequent core removal gives rise to "hollow" capsules ranging in size from nanometers to micrometers according to the sacrificial template used. ${ }^{2,3}$ Such polyelectrolyte capsules are built up of a polymer wall and have an inner cavity which may be loaded with various types of (therapeutic) molecules; literature reports on loading of the LbL capsules with various cargo molecules including low molecular weight drugs, ${ }^{4}$ polymers,${ }^{5}$ enzymes,${ }^{6-8} \mathrm{DNA}^{9}$ and protein antigens. ${ }^{3}$

The properties of polyelectrolyte capsules can be tuned by proper selection of the shell constituents and the core template used in the fabrication. ${ }^{10}$ The shell can be customized, as a variety of polymers can serve as building materials: going from synthetic polymers ${ }^{1,11}$ over biodegradable polymers. ${ }^{12-14}$ The majority of polyelectrolyte capsules reported today are composed of synthetic polymers, mainly the anionic poly(sodium)styrenesulfonate and the cationic poly(allylamine)hydrochloride. However, for pharmaceutical and biological settings, use of biocompatible and biodegradable materials (vulnerable to e.g. enzymatic degradation) is required..$^{15,16}$ As an example, our group encapsulated antigen proteins in polyelectrolyte microcapsules consisting of dextran sulfate and poly-L-arginine; we showed that such capsules degrade in dendritic cells through proteases and subsequently release the antigen. ${ }^{3,17}$ Besides tuning the permeability of the capsule shell by variations in shell thickness, the capsule surface can also be functionalized by e.g. poly(ethylene glycol), ${ }^{18}$ lipids, ${ }^{19}$ antibodies, ${ }^{20}$ dyes ${ }^{21}$ and nanoparticles. ${ }^{22,23}$

Two strategies have been envisaged for the encapsulation of substances in LbL capsules. In a first ("post-loading") approach, preformed capsules are loaded with molecules by temporarily manipulating the permeability of the capsule shell by changes in $\mathrm{pH},{ }^{24,25}$ ionic strength ${ }^{12}$ or solvent polarity ${ }^{7}$ of the 
dispersion. In the second approach, the substances of interest are already entrapped in the sacrificial template before the onset of the LbL coating and are thus present at the moment of core removal. It is clear that, depending on the type of drug to be loaded into the capsules, a proper selection of the sacrificial core is of outermost importance as both core removal and loading of preformed microcapsules often occur under rather extreme conditions (like changes in ionic strength or use of organic or highly acidic/alkaline solvents), which may have a negative impact on the biological activity of e.g. protein drugs. A variety of colloidal substrates has been used such as cross-linked melamine formaldehyde (MF), ${ }^{1}$ polystyrene, ${ }^{25} \mathrm{SiO}_{2},{ }^{26}$ and carbonate $\left(\mathrm{MnCO}_{3}, \mathrm{CdCO}_{3}, \mathrm{CaCO}_{3}\right)$ particles. ${ }^{27,28}$ These templates can be dissolved respectively by hydrochloric acid $(\mathrm{HCl})$, tetrahydrofuran (THF), hydrogenfluoride (HF) and ethylene diamine tetraacetic acid (EDTA).

The use of $\mathrm{CaCO}_{3}$ particles as decomposable templates offers interesting prospects to encapsulate proteins in polyelectrolyte capsules under mild conditions; indeed, the protein molecules can be coprecipitated at the moment of the $\mathrm{CaCO}_{3}$ core formation and after deposition of the multilayered shell, the core can be dissolved by $\mathrm{Ca}^{2+}$ complexation with an aqueous EDTA solution involving minimal stress for the encapsulated proteins. ${ }^{28}$ Understanding which parameters fundamentally influence the encapsulation efficiency of proteins in LbL microcapsules and whether protein loading of the capsules is well reproducible are basic requirements to judge whether LbL microcapsules will ever have a chance to become pharmaceutically used as protein carriers. Therefore, in the current study we aimed to investigate the encapsulation efficiency of proteins in dextran sulfate / poly-L-arginine microcapsules templated on $\mathrm{CaCO}_{3}$ cores, which we took as a model for biodegradable LbL microcapsules. We set out to elucidate how both the protein and microcapsule characteristics influence the encapsulation efficiency. Especially, we aimed at identifying which steps in the preparation of protein loaded LbL microcapsules most crucially determine the loading of polyelectrolyte microcapsules with proteins.

\section{Materials and Methods}


1. Materials. Albumin from human serum (HSA, $67 \mathrm{kDa}$, IEP 4,7), $\alpha$-lactalbumin (14 kDa, IEP 4,3), ethylenediamine-tetraacetic acid disodium salt (EDTA), IgG from bovine serum (150 kDa), calcium chloride $\left(\mathrm{CaCl}_{2}\right)$, sodium carbonate $\left(\mathrm{Na}_{2} \mathrm{CO}_{3}\right)$, dextran sulfate sodium salt $\left(\mathrm{M}_{\mathrm{w}} \sim 10 \mathrm{kDa}\right)$, poly-Larginine hydrochloride $\left(\mathrm{M}_{\mathrm{w}}>70 \mathrm{kDa}\right)$ and rhodamine isothiocyanate (RITC) were purchased from Sigma-Aldrich-Fluka. All materials were used without further purification. RITC labeled poly-Larginine was prepared by mixing poly-L-arginine and RITC 25:1 in 0.1 m borate buffer $\mathrm{pH}$ 8.5. Reaction was allowed overnight, residual RITC was removed by dialysis of the mixture against water using Spectra Por dialysis membrane. Lysozyme (14 kDa, IEP 11,1) was obtained from Fédération International Pharmaceutique (FIP).

Micro BCA Protein Assay Kit, Coomassie (Bradford) Protein Assay Kit and Pierce pre-coated iodination tubes were obtained from Thermo Scientific. Phosphate buffered saline (PBS) was purchased from Invitrogen. $\left[{ }^{99 m} \mathrm{Tc}\right]$ Human Serum Albumin and $\left[{ }^{111} \mathrm{In}\right] \mathrm{Ig}$ G (ProstaSint ${ }^{\circledR}$ ) were purchased from Mallinckrodt Medical and EUSA Pharma respectively. $\left[{ }^{131} \mathrm{I}\right]$ was obtained from Perkin Elmer.

2. Preparation of (protein loaded) calcium carbonate microparticles. $\mathrm{CaCO}_{3}$ particles were prepared by mixing an equal volume of a $\mathrm{Na}_{2} \mathrm{CO}_{3}(1.0 \mathrm{M})$ and a $\mathrm{CaCl}_{2}(1.0 \mathrm{M})$ solution under stirring, ${ }^{27}$ followed by washing with water. In order to obtain calcium carbonate particles loaded with protein, $100 \mu \mathrm{l}, 500 \mu \mathrm{l}$ or $1000 \mu \mathrm{l}$ of a $1 \mathrm{mg} / \mathrm{ml}$ solution of respectively lysozyme, $\alpha$-lactalbumin, HSA or IgG was added to the $\mathrm{CaCl}_{2}$ solution prior to mixing with the $\mathrm{Na}_{2} \mathrm{CO}_{3}$ solution. In this way protein molecules became entrapped within growing (precipitating) $\mathrm{CaCO}_{3}$ particles.

3. Preparation of hollow multilayer microcapsules. Polyelectrolyte microcapsules consisting of biodegradable dextran sulfate and poly-L-arginine were prepared by applying the LbL technique on the $\mathrm{CaCO}_{3}$ particles, as illustrated in Figure 1. Briefly, the $\mathrm{CaCO}_{3}$ particles were dispersed in a $2 \mathrm{mg} / \mathrm{ml}$ dextran sulfate solution containing $0.5 \mathrm{M} \mathrm{NaCl}$. After adsorption of the polyelectrolyte, the microparticles were collected by centrifugation for 3 minutes at 300 g. Subsequently, particles were washed twice with distilled water to remove excess dextran sulfate. In the next step, microparticles were incubated in a $1 \mathrm{mg} / \mathrm{ml}$ poly-L-arginine solution in $0.5 \mathrm{M} \mathrm{NaCl}$, followed by centrifugation and washing 
again. This LbL procedure was repeated until the desired number of bilayers was deposited. Removing the $\mathrm{CaCO}_{3}$ cores, by dispersing the $\mathrm{LbL}$ coated cores in a $0.2 \mathrm{M}$ EDTA solution, gave rise to hollow polyelectrolyte microcapsules.

\section{Characterization of polyelectrolyte microcapsules: Confocal laser scanning microscopy}

(CLSM). Confocal microscopy images of RITC labeled dextran sulfate / poly-L-arginine microcapsules were recorded using a Nikon C1si confocal laser scanning module attached to a motorized Nikon TE2000-E inverted microscope. Therefore a drop of microcapsule suspension was placed on a cover glass and analyzed with CLSM using a water immersion objective lens (Plan Apo 60X, NA 1.2, collar rim correction, Nikon).

5. Scanning electron microscopy (SEM). For scanning electron microscopy images, samples were prepared by dropping $\mathrm{CaCO}_{3}$ microparticles or $\mathrm{LbL}$ microcapsule suspension onto a silicon wafer, air dried and sputtered with gold. Observations were performed using a Quanta 200 FEG FEI scanning electron microscope operated at $5 \mathrm{kV}$.

6. Zetapotential measurement. The zetapotential of the microparticles was determined at each adsorption step in the LbL procedure with a Zetasizer nano series (Malvern). Therefore, the microparticles were dispersed in distilled water; the reported zetapotential value is the average of three consecutive measurements. The $\mathrm{CaCO}_{3}$ cores exhibited a zetapotential of $+6 \mathrm{mV} \pm 1,8 \mathrm{mV}$. Coprecipitation of $\alpha$-lactalbumin, $\mathrm{HSA}, \mathrm{IgG}$ or lysozyme with the $\mathrm{CaCO}_{3}$ cores resulted in zetapotential values of $-11,2 \mathrm{mV} \pm 2,8 \mathrm{mV}, \quad-15,1 \mathrm{mV} \pm 2,9 \mathrm{mV}, \quad-10,9 \mathrm{mV} \quad \pm 2,0 \mathrm{mV}$ and $+8,7 \mathrm{mV} \pm 0,9 \mathrm{mV}$, respectively.

7. Determination of encapsulation efficiency through spectrophotometric measurements. To determine the protein encapsulation efficiency in the $\mathrm{CaCO}_{3}$ particles, after the precipitation reaction the $\mathrm{CaCO}_{3}$ particles were centrifuged and the supernatans containing the non encapsulated protein was collected. Then, particles were washed twice with distilled water and washing waters were kept aside. For each concentration, particles were prepared in triplicate. The amount of protein in the supernatans and wash fractions was quantified spectrophotometrically by BCA and Bradford assays (described 
below). The protein encapsulation efficiency (EE) in the calcium carbonate particles was calculated using the following equation:

$$
\mathrm{EE} \%=\frac{\text { (total protein }- \text { free protein in supernatans) }}{\text { total protein }} \times 100 \%
$$

BCA protein determination: The Micro BCA assay kit (Pierce) was used for protein quantification. Protein standards of lysozyme, $\alpha$-lactalbumin, HSA or IgG (containing 0-25 $\mu \mathrm{g}$ of the protein per ml distilled water) were prepared. To each standard and unknown sample an equal volume of the BCA working reagent was added. Following mixing, samples were incubated at $37^{\circ} \mathrm{C}$ for 2 hours. After cooling to room temperature, the absorbance of the samples was measured at $562 \mathrm{~nm}$ (Shimadzu UV 1800). A linear relationship was observed between the concentration of the protein standards and the absorbance.

Coomassie (Bradford) protein determination: Supernatans and washing waters were collected and assayed spectrophotometrically at 595nm (Shimadzu UV 1800) with Bradford's protein assay method $(n=3) .{ }^{29}$ For standard curves, dilution series of lysozyme, $\alpha$-lactalbumin, HSA or IgG were prepared in the concentration range of $0-25 \mu \mathrm{g}$ protein per ml distilled water.

\section{Determination of encapsulation efficiency through radioactivity measurements:}

Radiolabeling of lysozyme and $\alpha$-lactalbumin. Lysozyme and $\alpha$-lactalbumin were labelled with $\left[{ }^{131} \mathrm{I}\right]$ using Pierce pre-coated iodination tubes (IODO-GEN). $\mathrm{Na}^{131} \mathrm{I}$ in PBS was added to the Pierce iodination tube and subsequently protein solution in PBS was added. Reaction was allowed to proceed for 15 minutes at room temperature. Afterwards, iodide was removed from the iodinated protein by gel filtration (on a PD-10 column using $\mathrm{CaCl}_{2}$ as mobile phase) and instant thin-layer chromatography (ITLC) was used to determine radiochemical purity.

9. Direct measurement by using radiolabeled proteins. Radiolabeled model proteins of varying molecular weight were used for encapsulation in the microcapsules (following the procedure described above), namely $\left[{ }^{131} \mathrm{I}\right] \alpha$-lactalbumin $(14 \mathrm{kDa}),\left[{ }^{131} \mathrm{I}\right]$ lysozyme (14 kDa), $\left[{ }^{99 \mathrm{~m}} \mathrm{Tc}\right]$ Human Serum Albumin 
(HSA, $67 \mathrm{kDa})$ and $\left[{ }^{111} \mathrm{In}\right] \mathrm{IgG}(150 \mathrm{kDa})$. All samples were made in triplicate. Aliquots of the washings, coating solutions, EDTA solution and the polyelectrolyte microcapsules dispersion were counted for radioactivity by a $\mathrm{NaI}(\mathrm{Tl})$ gamma scintillation counter (Packard Instruments) in order to investigate protein loss throughout the LbL procedure and to determine the final encapsulation efficiency in the microcapsules. The results were corrected for decay, and radioactivity concentrations are expressed as the percentage of the total radioactivity measured (mean \pm standard deviation values, $n=3$ ).

\section{Results and discussion}

\section{Characterization of hollow polyelectrolyte microcapsules templated on $\mathrm{CaCO}_{3}$ cores}

After mixing the $\mathrm{CaCl}_{2}$ and $\mathrm{Na}_{2} \mathrm{CO}_{3}$ solutions, the resulting $\mathrm{CaCO}_{3}$ microparticles (displaying a narrow size distribution $(2-4 \mu \mathrm{m})$; data not shown) were coated with bilayers of dextran sulfate and poly-L-arginine, as schematically illustrated in Figure 1.

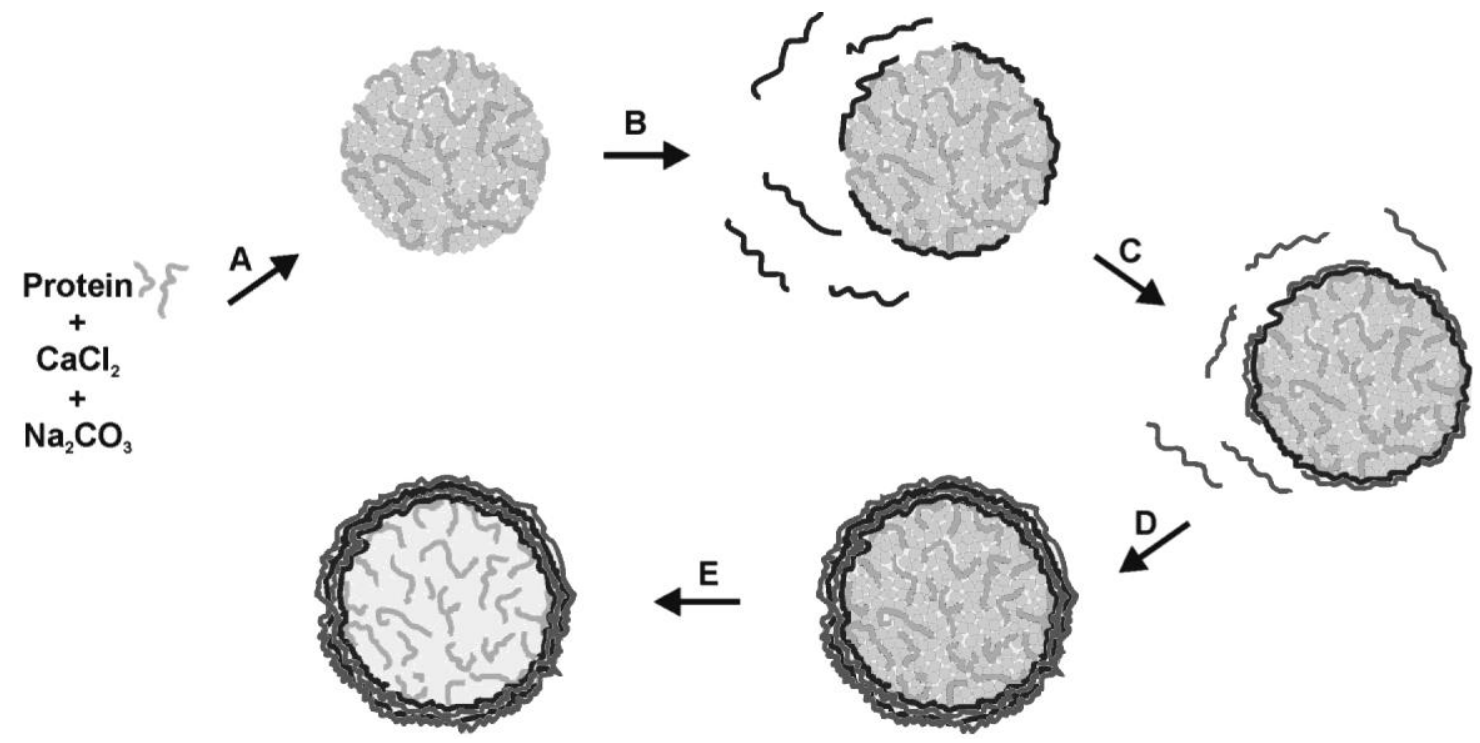

Figure 1. Schematic representation of the preparation of protein filled polyelectrolyte microcapsules.

(A) During calcium carbonate core formation the protein is coprecipitated, (B) followed by deposition of a first polyelectrolyte layer (i.e. dextran sulfate in this study) and (C) deposition of a second layer of an oppositively charged polyelectrolyte (i.e. poly-L-arginine in this study). (D) Consecutive LbL coating with dextran sulfate / poly-L-arginine until the desired number of bilayers is reached. (E) Finally, 
hollow microcapsules loaded with proteins are obtained by dissolution of the calcium carbonate core with EDTA.

The stepwise polyelectrolyte adsorption on the surface of the (porous) $\mathrm{CaCO}_{3}$ microparticles (SEM image in Figure 2B) was monitored by measuring the electrophoretic mobility after deposition of each polyelectrolyte layer (Figure 2A). Before $\mathrm{LbL}$ coating, the $\mathrm{CaCO}_{3}$ microparticles exhibited a zetapotential of $+6 \mathrm{mV}$ while it switched between $-25 \mathrm{mV}$ and $+21 \mathrm{mV}$ during the $\mathrm{LbL}$ procedure indicating the binding of respectively polyanions and polycations. When the desired number of polyelectrolyte bilayers was reached, hollow microcapsules were obtained by immersing the coated microparticles in an EDTA solution to dissolve the $\mathrm{CaCO}_{3}$ cores. In Figure $2 \mathrm{C}$ one can see such hollow LbL microcapsules in a collapsed state due to the drying of the sample before SEM imaging. Figure 2D shows a confocal microscopy image of hollow microcapsules which were fluorescently labeled by adsorption of one layer of RITC poly-L-arginine.
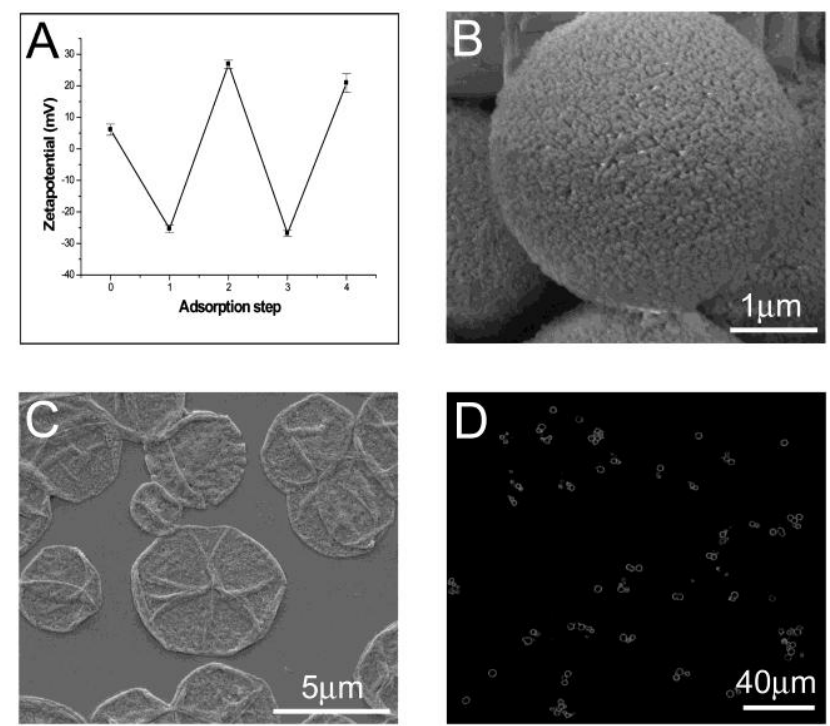

Figure 2. (A) Zetapotential measurements of $\mathrm{CaCO}_{3}$ particles sequentially coated by dextran sulfate and poly-L-arginine layers. The x-axis indicates the layer number: 0 corresponds to uncoated $\mathrm{CaCO}_{3}$ particles, 1 and 3 correspond to dextran sulfate deposition while 2 and 4 are steps in which poly-Larginine was deposited. The zetapotential alters between positive and negative values indicating deposition of respectively polyanions and polycations. (B) SEM images of $\mathrm{CaCO}_{3}$ microparticle (before $\mathrm{LbL}$ coating) and (C) hollow polyelectrolyte microcapsules after $\mathrm{CaCO}_{3}$ removal using EDTA. (D) 
Confocal image showing polyelectrolyte microcapsules consisting of 2 bilayers dextran sulfate / poly-Larginine; the microcapsules are fluorescently labeled by incorporation of RITC poly-L-arginine.

\section{Encapsulation efficiency of proteins in the $\mathrm{CaCO}_{3}$ cores}

In a first approach the loading of proteins in the $\mathrm{CaCO}_{3}$ particles was determined by measuring the amount of protein which was not entrapped, so named 'indirect measurements' in the continuation of this paper. The reason why we followed this indirect approach was the fact that, though protein molecules could be easily released out of the $\mathrm{CaCO}_{3}$ cores by dissolving them with EDTA, the protein concentration could not be determined through BCA and Bradford assays as EDTA interferes in these assays. The protein encapsulation efficiency of $\mathrm{CaCO}_{3}$ cores was studied for three negatively charged proteins with varying molecular weights, namely $\alpha$-lactalbumin $14 \mathrm{kDa}$, HSA $67 \mathrm{kDa}$ and IgG $150 \mathrm{kDa}$. On top we also investigated the effect of the protein's iso-electric-point (IEP) on the encapsulation efficiency. Therefore, we tested lysozyme ( $14 \mathrm{kDa})$ as a model protein that is positively charged under the conditions the proteins become entrapped in the growing $\mathrm{CaCO}_{3}$ particles.

\begin{tabular}{|c|c|c|c|c|}
\hline & & $100 \mu g^{*}$ & $500 \mu g^{*}$ & $1 \mathrm{mg} *$ \\
\hline \multirow[t]{4}{*}{ BCA } & $\alpha$-lactalbumin & $95.31 \pm 0.55$ & $94.91 \pm 0.60$ & $94.80 \pm 0.54$ \\
\hline & Lysozyme & $0.54 \pm 0.44$ & $0.72 \pm 1.10$ & $0.58 \pm 0.90$ \\
\hline & HSA & $92.70 \pm 0.65$ & $91.88 \pm 0.89$ & $92.53 \pm 0.44$ \\
\hline & IgG & $92.10 \pm 1.62$ & $92.75 \pm 0.18$ & $92.90 \pm 1.58$ \\
\hline \multirow[t]{2}{*}{ Bradford } & $\alpha$-lactalbumin & $95.29 \pm 0.91$ & $94.84 \pm 0.38$ & $94.90 \pm 0.20$ \\
\hline & Lysozyme & $0.06 \pm 1.58$ & $0.09 \pm 0.22$ & $0.09 \pm 0.67$ \\
\hline
\end{tabular}


Indicates the amount of protein used in the experiments

Table 1. Encapsulation efficiency (in \%) of proteins in $\mathrm{CaCO}_{3}$ particles, as obtained through $\mathrm{BCA}$ or Bradford assay $(\mathrm{n}=3)$.

Table 1 shows the results. For the negatively charged proteins $\alpha$-lactalbumin, HSA and IgG, high loading efficiencies (i.e. over 90\%) were observed; thus both low and high molecular weight negatively charged proteins become well entrapped by $\mathrm{CaCO}_{3}$ cores. Also note that, for the protein concentration range we tested, the concentration of the protein did not affect the encapsulation efficiency of the proteins in the $\mathrm{CaCO}_{3}$ cores. In clear contrast, however, less than $1 \%$ of the positively charged lysozyme became entrapped in the $\mathrm{CaCO}_{3}$ cores. Apparently, the high IEP of the lysozyme hampered the protein$\mathrm{CaCO}_{3}$ interaction leading to a very low amount of protein which becomes finally entrapped. The exact reason for this remains speculative though it is reasonable to assume that electrostatic forces play part in the adsorption process. Because both lysozyme and the surface of the $\mathrm{CaCO}_{3}$ particles (Figure 2A) are positively charged, electrostatic repulsions may inhibit the loading of the particles with lysozyme. Volodkin et al. also noticed that the charge of both the macromolecules (proteins and dextran) and the microparticles influence the affinity of the macromolecules to the carbonate surface and thus the adsorption on the $\mathrm{CaCO}_{3}$ surface; they showed that electrostatic interactions are playing a major contribution in this phenomenon. ${ }^{27}$

In a second approach the protein loading in the $\mathrm{CaCO}_{3}$ particles was determined through radioactivity measurements. Therefore, radiolabeled $\left[{ }^{131} \mathrm{I}\right] \alpha$-lactalbumin, $\left[{ }^{131} \mathrm{I}\right]$ lysozyme, $\left[{ }^{99 \mathrm{~m}} \mathrm{Tc}\right] \mathrm{HSA}$ or $\left[{ }^{111} \mathrm{In}\right] \mathrm{IgG}$ were entrapped in $\mathrm{CaCO}_{3}$ particles during the precipitation reaction. To determine the nonencapsulated fraction, the radioactivity of respectively the supernatans and washing waters was measured. Moreover the $\mathrm{CaCO}_{3}$ particles were dissolved in EDTA solution to release the entrapped protein and radioactivity was measured. 


\begin{tabular}{lccc}
\hline & $100 \mu \mathrm{g}^{*}$ & $500 \mu \mathrm{g}^{*}$ & $1 \mathrm{mg}^{*}$ \\
\hline$\left[{ }^{131} \mathrm{I}\right] \alpha$-Lactalbumin & $95.68 \pm 0.26$ & $96.03 \pm 0.2$ & $95.68 \pm 0.26$ \\
${ }^{131}$ I]Lysozyme & $0.84 \pm 0.39$ & $0.87 \pm 0.20$ & $0.60 \pm 0.20$ \\
{$\left[{ }^{99 \mathrm{~m}}\right.$ Tc]HSA } & $93.66 \pm 0.48$ & $94.07 \pm 0.80$ & $94.14 \pm 0.78$ \\
{$\left[{ }^{111}\right.$ In] IgG } & $90.47 \pm 0.77$ & $93.37 \pm 0.44$ & $94.57 \pm 0.78$ \\
\end{tabular}

*Indicates the amount of protein used in the experiments

Table 2. Encapsulation efficiency (in \%) of proteins in $\mathrm{CaCO}_{3}$ particles as obtained through radioactivity measurements after dissolution of the cores in EDTA, $(n=3)$.

As depicted in Table 2 high loadings were obtained with the negatively charged proteins $\left[{ }^{131} \mathrm{I}\right] \alpha-$ lactalbumin, $\left[{ }^{99 \mathrm{~m}} \mathrm{Tc}\right] \mathrm{HSA}$ and $\left[{ }^{111} \mathrm{In}\right] \mathrm{IgG}$, in good agreement with the results obtained through Bradford and BCA assaying. Also, $\left[{ }^{131} \mathrm{I}\right]$ lysozyme did not coprecipitate with the $\mathrm{CaCO}_{3}$ particles. The results in Table 2 suggest that there is no influence of the protein' s molecular weight but a major influence of its charge on the entrapment efficiency in $\mathrm{CaCO}_{3}$ particles. Overall, coprecipitation of (negatively charged) proteins and calcium carbonate is an excellent method for achieving high entrapment efficiencies; this is attractive as most therapeutically relevant proteins are negatively charged at physiological conditions.

\section{Encapsulation efficiency of proteins in LbL microcapsules}

In a next step we were interested to know the encapsulation efficiency of the proteins in the LbL microcapsules. The preparation of the LbL microcapsules took off with the entrapment of protein in $\mathrm{CaCO}_{3}$ particles by coprecipitation as illustrated in Figure 1, the desired number of polyelectrolyte bilayers was deposited on the particles. The preparation came to an end by dissolving the $\mathrm{CaCO}_{3}$ cores with EDTA yielding hollow microcapsules containing protein in their aqueous cavity. We aimed (a) to determine the (overall) encapsulation efficiency of proteins in the LbL microcapsules and, especially, 
(b) to identify which steps in the preparation of LbL microcapsules are the most critical in the encapsulation process.

Microcapsules were built up of bilayers of dextran sulfate/poly-L-arginine. To determine the encapsulation efficiency of proteins in such LbL microcapsules we could no longer make use of the BCA or Bradford assays as the encapsulated proteins could not be released from the microcapsules (due to the LbL shell). Though dextran sulfate / poly-L-arginine LbL layers can be degraded upon exposure to proteolytic enzymes, ${ }^{3,14}$ releasing the encapsulated proteins through enzymatic degradation of the shells was not an option as the poly-L-arginine present in the LbL layers would interfere in the BCA and Bradford assays. We were thus limited to the use of radiolabeled proteins to determine the protein encapsulation efficiency in the LbL microcapsules by measuring protein while it is present in the microcapsules' cavity. 


\begin{tabular}{|c|c|c|c|c|c|}
\hline & & $\begin{array}{l}\text { Number } \\
\text { of bilayers }\end{array}$ & $\begin{array}{c}1^{\text {st }} \text { dextran } \\
\text { sulfate layer }\end{array}$ & EDTA & $\begin{array}{l}\text { Polyelectrolyte } \\
\text { microcapsules }\end{array}$ \\
\hline \multirow[t]{6}{*}[{}^{131}I]{$\alpha$-lactalbumin } & $100 \mu \mathrm{g}$ & 1 & $12.36 \pm 4.60$ & $77.46 \pm 6.24$ & $3.91 \pm 0.16$ \\
\hline & & 2 & & $67.74 \pm 1.52$ & $8.24 \pm 0.46$ \\
\hline & & 3 & & $56.97 \pm 4.75$ & $9.79 \pm 0.33$ \\
\hline & $1 \mathrm{mg}$ & 1 & $17.17 \pm 2.13$ & $72.21 \pm 1.02$ & $4.61 \pm 0.89$ \\
\hline & & 2 & & $64.80 \pm 0.66$ & $6.98 \pm 0.21$ \\
\hline & & 3 & & $62.32 \pm 1.37$ & $6.90 \pm 0.14$ \\
\hline \multirow[t]{6}{*}[{}^{99\mathrm{m}}\mathrm{Tc}]{$\mathrm{HSA}$} & $100 \mu \mathrm{g}$ & 1 & $9.95 \pm 1.55$ & $70.11 \pm 3.63$ & $9.43 \pm 1.28$ \\
\hline & & 2 & & $52.89 \pm 4.54$ & $24.04 \pm 4.31$ \\
\hline & & 3 & & $54.51 \pm 6.16$ & $23.44 \pm 4.17$ \\
\hline & $1 \mathrm{mg}$ & 1 & $10.21 \pm 1.04$ & $68.73 \pm 0.18$ & $12.14 \pm 0.17$ \\
\hline & & 2 & & $53.83 \pm 4.16$ & $23.73 \pm 1.05$ \\
\hline & & 3 & & $57.18 \pm 3.07$ & $19.01 \pm 1.33$ \\
\hline \multirow[t]{6}{*}[{}^{111}\operatorname{ln}]{$\lg G$} & $100 \mu \mathrm{g}$ & 1 & $4.61 \pm 0.78$ & $30.06 \pm 4.16$ & $57.83 \pm 3.50$ \\
\hline & & 2 & & $12.57 \pm 1.76$ & $70.96 \pm 1.79$ \\
\hline & & 3 & & $11.58 \pm 1.90$ & $69.39 \pm 0.47$ \\
\hline & $1 \mathrm{mg}$ & 1 & $4.31 \pm 0.68$ & $30.14 \pm 0.27$ & $60.16 \pm 1.40$ \\
\hline & & 2 & & $17.94 \pm 1.66$ & $69.22 \pm 2.13$ \\
\hline & & 3 & & $12.65 \pm 2.86$ & $72.00 \pm 3.53$ \\
\hline
\end{tabular}

Table 3. Loss of protein (\%) at deposition of the $1^{\text {st }}$ dextran sulfate layer and upon dissolving the $\mathrm{CaCO}_{3}$ cores using EDTA, and encapsulation efficiency (in \%) of proteins in the LbL microcapsules ( $\mathrm{n}=3$ ). 
Table 3 shows the results on the encapsulation of $\left[{ }^{131} \mathrm{I}\right] \alpha$-lactalbumin, $\left[{ }^{99 \mathrm{~m}} \mathrm{Tc}\right]$ HSA and $\left[{ }^{111} \mathrm{In}\right] \mathrm{IgG}$ in microcapsules built up of respectively one, two or three bilayers of dextran sulfate / poly-L-arginine.

Upon applying the first dextran sulfate layer on the $\mathrm{CaCO}_{3}$ cores we observed a partial loss of proteins (Table 3), this was also observed for $\alpha$-lactalbumin by others. ${ }^{27}$ This loss occurred for the different proteins, however to a lower extent in the case of the larger $150 \mathrm{kDa} \mathrm{IgG}$; on average $14 \%$ of $\alpha$ lactalbumin, $10 \%$ of HSA while only $4 \%$ of $\mathrm{IgG}$ was released. We hypothesize that upon $\mathrm{CaCO}_{3} \mathrm{core}$ formation protein molecules do not only become entrapped within the cores, though part of them becomes adsorped on the surface of the $\mathrm{CaCO}_{3}$ particles. Likely, the huge number of dextran sulfate chains in the "coating solution" compete with the (negatively charged) proteins for surface binding. The reason why a lower percentage of the higher molecular weight HSA and IgG seem to be released is rather unclear; however, one could argue that the higher the protein's molecular weight, the higher the number of interactions between a protein molecule and a $\mathrm{CaCO}_{3}$ core, the more difficult it might be for dextran sulfate chains to "liberate" the surface adsorped proteins. Importantly, we observed that further applying polyelectrolyte layers on the dextran sulfate coated $\mathrm{CaCO}_{3}$ cores did no longer cause release of proteins (data not shown).

In a next step, the $\mathrm{LbL}$ coated $\mathrm{CaCO}_{3}$ templates were dispersed in EDTA. We observed that in this step a 'rearrangement' of the polyelectrolyte layers occurs; indeed, after dissolution of the $\mathrm{CaCO}_{3}$ we noticed a change in zetapotential (data not shown; in agreement with previous observations ${ }^{30}$ ). Upon dissolving the $\mathrm{CaCO}_{3}$ we noticed a spectacular loss of proteins from the microcapsules: all data are overviewed in Table 3 and Figures 3 and 4. 


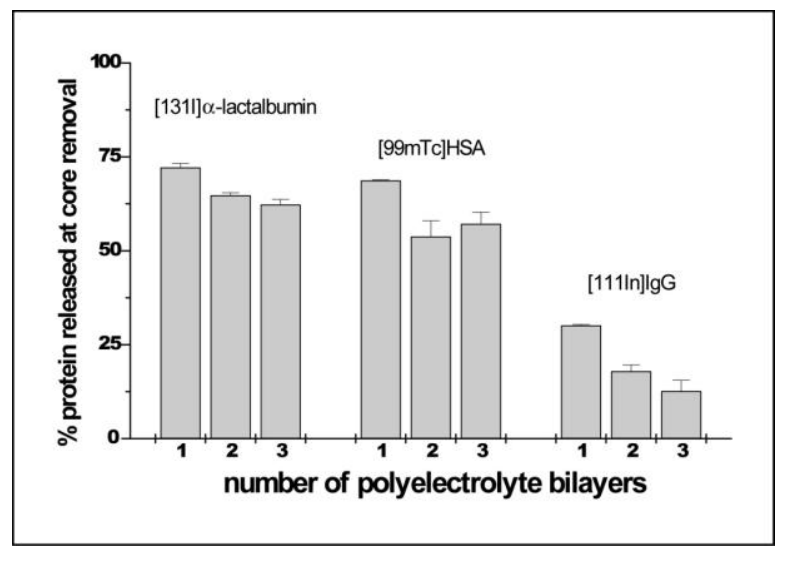

Figure 3. Loss of protein from microcapsules, composed of different number of dextran sulfate / polyL-arginine bilayers, upon dissolution of the $\mathrm{CaCO}_{3}$ cores with EDTA, (1 $\mathrm{mg}$ of protein was used in the experiments, $n=3)$.

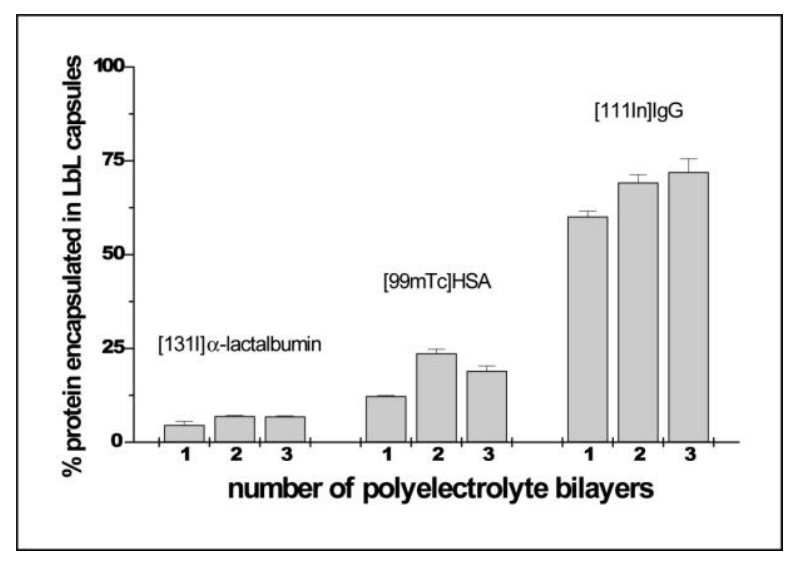

Figure 4. Encapsulation efficiency (in \%) of proteins in LbL microcapsules, (1 mg of protein was used in the experiments, $n=3$ ).

We observed that for $\alpha$-lactalbumin on average $75 \%$ of the initial protein amount was set free upon dissolving cores of so named "one bilayer microcapsules" (which are $\mathrm{CaCO}_{3}$ particles coated with one bilayer). When the $\mathrm{CaCO}_{3}$ were coated with respectively two and three bilayers, less $\alpha$-lactalbumin became released. In case of HSA, “one bilayer microcapsules" lost around $70 \%$ of the protein compared to $55 \%$ for the two and three bilayered microcapsules. For IgG, one bilayer microcapsules released $30 \%$, only $14 \%$ of $\operatorname{IgG}$ became lost for the two and three bilayered capsules. 
Clearly, loss of protein upon dissolution of the $\mathrm{CaCO}_{3}$ is thus dependent on the number of bilayers which coat the $\mathrm{CaCO}_{3}$. The more bilayers, the less permeable the $\mathrm{LbL}$ shell, the lower the loss of protein. ${ }^{31}$ Especially, when comparing one and two bilayered microcapules in case of all modelproteins a striking difference in protein loss catches the eye: decreasing release with increasing number of bilayers. However comparing the two and three bilayered microcapsules, we observed that for the low molecular weight protein $\alpha$-lactalbumin the release at core dissolution is still decreasing with increasing bilayer number, whereas for the higher molecular weight proteins HSA and IgG, there are no significant differences in protein release observed indicating that the number of bilayers is not the only factor determining the final encapsulation efficiency in LbL capsules. One could suggest that the loss of protein could be even more lowered by further increasing the number of bilayers, which is of course true. Though, for drug delivery purposes a lower number of bilayers might be desirable. Indeed, it has been shown that antigen release kinetics from carriers may impact the immunological outcome; ${ }^{32,33}$ as a consequence, when microcapsules are used to deliver e.g. protein antigen to dendritic cells, the microcapsules should become degraded over a relatively short time so that the antigen is set free for degradation and subsequent presentation of the antigenic peptides on MHC molecules by the dendritic cell.

The effect of the protein's molecular weight on the encapsulation efficiency in LbL microcapsules was further investigated. As shown in Table 3 and Figures 3 and 4, the higher the molecular weight of the protein the lower the loss upon dissolving the $\mathrm{CaCO}_{3}$ of the $\mathrm{LbL}$ microcapsules. This phenomenon is reasonable to expect and can obviously be explained by a more limited diffusion of larger molecules through the LbL shell.

\section{Conclusions}

Understanding which parameters fundamentally influence the encapsulation efficiency of proteins in LbL microcapsules is crucial information for the further development of LbL microcapsules as protein carriers in pharmacy. Therefore, to get insight in this matter, and, especially, to be able to optimize 
protein encapsulation in LbL microcapsules, we studied all steps in the preparation of microcapsules where loss of protein load might occur. Our experiments revealed a high entrapment efficiency $(>90 \%)$ of negatively charged proteins in $\mathrm{CaCO}_{3}$ microparticles; this appeared to be extremely dependent on the IEP of the protein: positively charged lysozyme became (nearly completely) excluded from $\mathrm{CaCO}_{3}$ microparticles.

Applying dextran sulfate as first polyelectrolyte layer on the protein loaded $\mathrm{CaCO}_{3}$ cores resulted in loss of protein which we attributed to displacement of surface adsorped protein in favour of dextran sulfate; the higher the molecular weight of the protein the lower the amount of protein which was lost. Deposition of additional polyelectrolyte layers did not result in a further loss of proteins. By far the most critical step turned out to be the dissolution of the $\mathrm{CaCO}_{3}$ cores of the $\mathrm{LbL}$ microcapsules. We showed that the extent of protein loss at this critical step was dependent on (i) the protein's molecular weight and (ii) the number of bilayers the microcapsules were comprised of. LbL microcapsules consisting of several polyelectrolyte bilayers kept the proteins better as their shell is less permeable. Especially, compared to lower molecular weight proteins, higher molecular weight proteins seemed to be much better retained by the capsules upon dissolving the calcium carbonate cores.

Our data show that major differences exist in the encapsulation efficiency of proteins in LbL microcapsules, with values ranging from $4 \%$ to over $70 \%$. It was demonstrated that for $\alpha$-lactalbumin the one bilayer microcapsules retained on average only $4 \%$ of the initial protein amount, the two and three bilayer microcapsules kept about 7-9\%. In case of HSA, one bilayer microcapsules withhold 9 to $12 \%$ of the protein compared to 19 to $24 \%$ for the two and three bilayer microcapsules. For IgG the encapsulation efficiencies started at $58 \%$ for the one bilayer microcapsules and even rised above $70 \%$ for the two and three bilayer microcapsules. We believe that this quantitative information should be taken into account in all further studies in which protein loaded LbL microcapsules will be investigated with respect to one or another objective. 


\section{References}

(1) Sukhorukov, G. B.; Donath, E.; Lichtenfeld, H.; Knippel, E.; Knippel, M.; Budde, A.; Mohwald, H. Colloid. Surface. A 1998, 137, 253-266.

(2) Caruso, F.; Caruso, R. A.; Mohwald, H. Science 1998, 282, 1111-1114.

(3) De Koker, S.; De Geest, B. G.; Singh, S. K.; De Rycke, R.; Naessens, T.; Van Kooyk, Y.; Demeester, J.; De Smedt, S. C.; Grooten, J. Angew. Chem. Int. Ed. 2009, 48, 8485-8489.

(4) Qiu, X. P.; Leporatti, S.; Donath, E.; Mohwald, H. Langmuir 2001, 17, 5375-5380.

(5) Radtchenko, I. L.; Sukhorukov, G. B.; Mohwald, H. Colloid. Surface. A 2002, 202, 127-133.

(6) Caruso, F.; Trau, D.; Mohwald, H.; Renneberg, R. Langmuir 2000, 16, 1485-1488.

(7) Lvov, Y.; Antipov, A. A.; Mamedov, A.; Mohwald, H.; Sukhorukov, G. B. Nano Lett. 2001, 1, 125-128.

(8) Gao, C. Y.; Liu, X. Y.; Shen, J. C.; Mohwald, H. Chem. Commun. 2002, 17, 1928-1929.

(9) Shchukin, D. G.; Patel, A. A.; Sukhorukov, G. B.; Lvov, Y. M. J. Am. Chem. Soc. 2004, 126, 3374-3375.

(10) Wang,Y.; Angelatos, A. S.; Caruso, F. Chem. Mater. 2008, 20, 848-858

(11) Lourenco, J. M. C.; Ribeiro, P. A.; do Rego, A. M. B.; Fernandes, F. M. B.; Moutinho, A. M. C.; Raposo, M. Langmuir 2004, 20, 8103-8109.

(12) Schuler, C.; Caruso, F. Biomacromolecules 2001, 2, 921-926.

(13) Hiller, S.; Leporatti, S.; Schnackel, A.; Typlt, E.; Donath, E. Biomacromolecules 2004, 5, 15801587. 
(14) De Geest, B. G.; Vandenbroucke, R. E.; Guenther, A. M.; Sukhorukov, G. B.; Hennink, W. E.; Sanders, N. N.; Demeester, J.; De Smedt, S. C. Adv. Mater. 2006, 18, 1005-1009.

(15) De Koker, S.; De Geest, B. G.; Cuvelier, C.; Ferdinande, L.; Deckers, W.; Hennink,W. E.; De Smedt, S. C.; Mertens, N. Adv. Funct. Mater. 2007, 17, 3754-3763.

(16) Ochs, C. J.; Such, G. K.; Stadler, B.; Caruso, F. Biomacromolecules, 2008, 9, 3389-3396.

(17) De Koker, S.; Naessens, T.; De Geest, B. G.; Bogaert, P.; Demeester, J.; De Smedt, S. C.; Grooten, J. J. Immunol. 2010, 184, 203-211.

(18) Wattendorf, U.; Kreft, O.; Textor, M.; Sukhorukov, G. B.; Merkle, H. P. Biomacromolecules 2008, 9, 100-108.

(19) Fischlechner, M.; Zschornig, O.; Hofmann, J.; Donath, E. Angew. Chem. Int. Ed. 2005, 44, $2892-$ 2895.

(20) Cortez, C.; Tomaskovic-Crook, E.; Johnston, A. P. R.; Radt, B.; Cody, S. H.; Scott, A. M.; Nice, E. C.; Heath, J. K.; Caruso, F. Adv. Mater. 2006, 18, 1998-2003.

(21) Tao, X.; Li, J. B.; Mohwald, H. Chem-Eur. J. 2004, 10, 3397-3403.

(22) Lu, Z. H.; Prouty, M. D.; Guo, Z. H.; Golub, V. O.; Kumar, C. S. S. R.; Lvov, Y. M. Langmuir 2005, 21, 2042-2050.

(23) Angelatos, A. S.; Radt, B.; Caruso, F. J. Phys. Chem. B 2005, 109, 3071-3076.

(24) Sukhorukov, G. B.; Antipov, A. A.; Voigt, A.; Donath, E.; Mohwald, H. Macromol. Rapid Comm. 2001, 22, 44-46.

(25) Dejugnat, C.; Halozan, D.; Sukhorukov, G. B. Macromol. Rapid Comm. 2005, 26, 961-967.

(26) Peyratout, C. S.; Dahne, L. Angew. Chem. Int. Ed. 2004, 43, 3762-3783. 
(27) Sukhorukov, G. B.; Volodkin, D. V.; Gunther, A. M.; Petrov, A. I.; Shenoy, D. B.; Mohwald, H. J. Mater. Chem. 2004, 14, 2073-2081.

(28) Volodkin, D. V.; Larionova, N. I.; Sukhorukov, G. B. Biomacromolecules 2004, 5, 1962-1972.

(29) Bradford, M. M. Anal. Biochem. 1976, 72, 248-254.

(30) De Haes, W.; De Koker, S.; Pollard, C.; Atkinson, D.; Vlieghe, E.; Hoste, J.; Rejman, J.; De Smedt, S. C.; Grooten, J.; Vanham, G.; Van Gulck, E. Mol. Ther. 2010, 18, 1408-1416.

(31) She, Z.; Antipina, M. N.; Li, J.; Sukhorukov, G. B. Biomacromolecules 2010, 11, 1241-1247.

(32) Howland, S. W.; Wittrup, K. D. J. Immunol. 2008, 180, 1576-1583.

(33) Broaders, K. E.; Cohen, J. A.; Beaudette, T. T.; Bachelder, E. M.; Frechet, J. M. J. P. Natl. Acad. Sci. USA 2009, 106, 5497-5502. 
For Table of Contents Use Only

Encapsulation Performance of Layer-by-Layer Microcapsules for Proteins

Marie-Luce De Temmerman, Jo Demeester, Filip De Vos, and Stefaan C. De Smedt

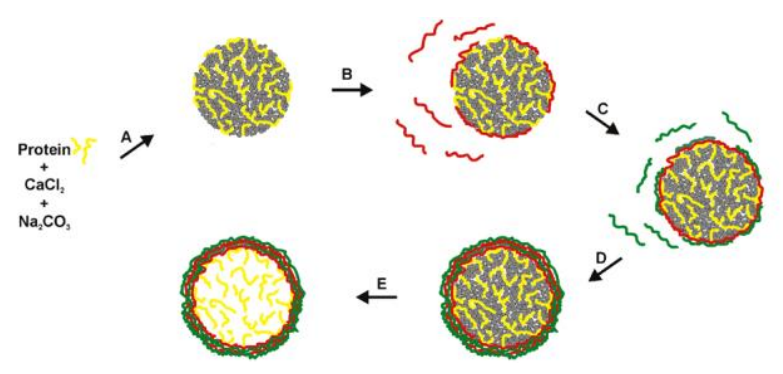

